\title{
Effect of a chamber orchestra on direct sound and early reflections for performers on stage: A Boundary Element Method study
}

\author{
Lilyan Panton* and Damien Holloway \\ School of Engineering and ICT, University of Tasmania, Hobart, Tasmania, Australia \\ Densil Cabrera \\ Faculty of Architecture, Design and Planning, University of Sydney, Sydney, New South Wales, Australia
}

(Dated: March 27, 2017)

\begin{abstract}
Early reflections are known to be important to musicians performing on stage, but acoustic measurements are usually made on empty stages. This work investigates how a chamber orchestra setup on stage affects early reflections from the stage enclosure. A boundary element method (BEM) model of a chamber orchestra is validated against full scale measurements with seated and standing subjects in an anechoic chamber and against auditorium measurements, demonstrating that the $\mathrm{BEM}$ simulation gives realistic results. Using the validated BEM model, an investigation of how a chamber orchestra attenuates and scatters both the direct sound and the first-order reflections is presented for two different sized shoe-box stage enclosures. The first-order reflections from the stage are investigated individually: at and above the $250 \mathrm{~Hz}$ band, horizontal reflections from stage walls are attenuated to varying degrees, while the ceiling reflection is relatively unaffected. Considering the overall effect of the chamber orchestra on the direct sound and first-order reflections differences of $2-5 \mathrm{~dB}$ occur in the $1000 \mathrm{~Hz}$ octave band when the ceiling reflection is excluded (slightly reduced when including the unobstructed ceiling reflection). A tilted side wall case showed the orchestra has a reduced effect with a small elevation of the lateral reflections.
\end{abstract}

PACS numbers: PACS: 43.55.Br, 43.20.El

\section{INTRODUCTION}

Acoustic parameters, derived from impulse response measurements on stage, have been used with limited success to characterize the subjective experience of musicians playing on stage. For example, in spite of their general acceptance for stage acoustics characterization, Dammerud $^{1}$ did not find a correlation between subjective musician ratings and the $S T_{\text {early }}$ parameter proposed by $\mathrm{Gade}^{2}$. One reason for the lack of subjective relevance of such stage acoustic measures may be that they are often derived from measurements undertaken on unoccupied stages, whereas in the real playing experience the on-stage sound field may be impacted by the presence of on-stage objects, including the performers. Several previous studies, focusing on a symphony orchestra setup on stage have demonstrated that stage objects (musicians, stands and instruments) do significantly affect on-stage sound fields ${ }^{1,3-5}$. However, measurements on stage without stage objects present, or with only chairs and music stands, are still common because of the practical difficulties and lack of repeatability associated with doing acoustic measurements with an orchestra present.

Acoustic parameters defined with 'early' time intervals are commonly used to assess ensemble playing conditions. The time period used to define 'early' varies: $\mathrm{Gade}^{6}$ has defined 20-100 ms as 'early' for the stage support parameter $S T_{\text {early }}$, Dammerud ${ }^{1}$ has defined early as $0-80 \mathrm{~ms}$ for $G_{\mathrm{e}}$ (early sound strength) and also examined $G_{7-50}$ with a time interval of 7-50 ms. Others have also investigated very early time intervals, such as $L Q_{7-40}$ defined with a time interval of $7-40 \mathrm{~ms}^{7}$. The support measures have also been adapted to allow for across-stage measurements with source-receiver distance greater than $1 \mathrm{~m}$ by Wenmaekers et al. ${ }^{8}$, denoted as $S T_{\text {early,d, with the early }}$ time interval defined as ' $10-$ delay' ms, where delay is the source-receiver distance divided by speed of sound.

Dammerud and Barron ${ }^{3}$ completed an experimental study of on-stage attenuation using a scale model (1:25) of a symphony orchestra, and found that for the $500 \mathrm{~Hz}$ octave and above there was significant deviation from the empty stage result. Dammerud and Barron's scale model did not include a stage shell, meaning only attenuation of the direct sound and floor reflection was considered. They found attenuation of $-0.8 \mathrm{~dB} / \mathrm{m}$ for source-receiver distances in the range $3-16 \mathrm{~m}$ at $1 \mathrm{kHz}$. They also analyzed full-scale measurements on a real stage with an orchestra, originally conducted by Ikeda et al. ${ }^{9}$, and found attenuation of $-0.7 \mathrm{~dB} / \mathrm{m}$ for source-receiver distances in the range $2-6 \mathrm{~m}$ at $1 \mathrm{kHz}$. In full-scale measurements conducted by Skålevik ${ }^{4}$, the effect of a symphony orchestra on on-stage sound fields was also noted as significant for the $500 \mathrm{~Hz}$ octave band and above for a single path through a full symphony orchestra (path length $11.7 \mathrm{~m}$ ).

Wenmaekers et al. ${ }^{5}$ have examined the effect of a symphony orchestra on stage, using a dummy orchestra consisting of mannequins (the sound absorption properties of these mannequins validated with measurements in a reverberation chamber). The dummy orchestra was used on fives stages, and attenuation of direct sound was examined to compare to results from Dammerud and Barron ${ }^{3}$. Attenuation by the dummy orchestra was $3-6 \mathrm{~dB}$ greater than by Dammerud and Barron's scale model orchestra for the same source-receiver dis- 
tances through the orchestra (distances between 3-16 m). Wenmaekers et al. also considered the effect of the orchestra on early sound parameters (namely $S T_{\text {early }}$ and $S T_{\text {early,d }}$ ); the difference between occupied and empty condition was $2 \mathrm{~dB}$ for $S T_{\text {early }}$ (slightly less for $S T_{\text {early,d }}$ for a $1 \mathrm{~m}$ source-receiver distance).

Other work by Dammerud ${ }^{1}$ has used ray-tracing to model a symphony orchestra on stage, using the scale model results (including a scale model stage enclosure) for validation. However, Dammerud found poor agreement with the scale model for source-receiver distances between 5 and $9 \mathrm{~m}$. In the ray-tracing model the musicians (and stands and instruments) were represented as simplified benches, and high scattering coefficients were applied so that the actual shape and angle of the benches had minimal impact on results. This ray-tracing orchestra model appears to be an inadequate model to investigate within-orchestra attenuation for source-receiver paths between 5 and $9 \mathrm{~m}$ (such as within a chamber orchestra), because wave interference effects, diffraction and specific characteristics of scattering are not fully accounted for by ray-tracing methods ${ }^{1}$.

No studies appear in the literature focusing on how a smaller chamber orchestra affects on-stage sound fields, or the applicability of standard stage measurements for such a group. Chamber orchestras, unlike symphony orchestras, typically rehearse and perform without a conductor, so arguably their acoustic needs are more critical, or at the very least different. Additionally, a chamber orchestra will often perform standing, whereas symphony orchestras perform seated, meaning different source-receiver heights are needed.

Other studies have focused on sound absorption by standing audiences ${ }^{10,11}$ and have considered the change in reverberant or late parameters with and without the audience present. For an orchestra on stage it is important to consider how sound propagates through the orchestra (to consider ease of musical communication), as well the effect of the orchestra as a whole on audience measures.

In this study, a boundary element method (BEM) model of a chamber orchestra has been developed to investigate the on-stage acoustic conditions for a chamber orchestra. This model has been validated against measurements in a hemi-anechoic chamber. To further validate the BEM model for this investigation, full scale measurements with a real chamber orchestra were also conducted in an auditorium. The full scale measurements showed that the BEM produces realistic results, and the BEM model was then used to investigate two different stage enclosure sizes. Traditionally, stage parameters have been omnidirectional, however recently studies have begun to consider whether the directionality of on-stage sound fields is subjectively important to musicians ${ }^{12-14}$. This study focuses on the effect of the orchestra on direct sound and also first-order enclosure reflections, and each first-order reflection is investigated individually to demonstrate the effect of the orchestra depending on the arrival direction.

\section{BEM MODELLING: GENERAL CONSIDERATIONS AND VALIDATION}

In this section the validation undertaken for the BEM model is summarized. The BEM analysis was conducted using FastBEM(B). To ensure accurate results, a mesh size of at least an eighth of a wavelength was always used. FastBEM offers a full boundary element method solver, which solves the full Helmholtz equations, and accelerated methods. In this work the adaptive cross approximation (ACA) solver, which uses a hierarchical matrix partitioning structure, has been used.

\section{A. Validation setup used}

To validate their scale model, Dammerud and Barron ${ }^{3}$ tested a simplified configuration. They compared results to unpublished full scale measurements undertaken by $\operatorname{Krokstad}^{15}$, and matched the absorption for the scale model musicians to the absorption found in full scales measurements by Harwood et al. ${ }^{16}$. A more recent study by Jang and Jeon ${ }^{17}$ also examined absorption of seated musicians in a reverberation chamber, and found some variation depending on factors like clothing type, instruments and seating density, nevertheless overall good agreement was observed with Harwood et al. ${ }^{16}$. Krokstad's full scale measurements with seated musicians involved a simplified case of two lines of seated people (one line with six people and one line with five people) in front of a source (three source heights were used). The results are presented with the use of frequency averaging and source-receiver height averaging. Dammerud and Barron states that the scale model results were within +1 and $-2 \mathrm{~dB}$ at $1 \mathrm{kHz}$ and $2 \mathrm{kHz}$ compared to the measurements by Krokstad ${ }^{15}$, but do not provide information on the agreement at other frequencies. Due to lack of details known about Krokstad's experiments a similar experimental setup has been recreated in the present study to provide a stronger basis for model validation and avoiding the use of averaging.

The authors replicated Krokstad's measurements in a hemi-anechoic chamber (using 6 seated subjects, rather than the 11 used by Krokstad). Sound propagating around standing people was also investigated because chamber orchestras frequently perform with musicians (violins and violas) standing. The 6 seated or standing subjects were arranged as shown in Figure 1. The room's anechoic lining is specified as such at and above the $200 \mathrm{~Hz} \mathrm{1/3-octave} \mathrm{band.} \mathrm{The} \mathrm{chamber} \mathrm{internal} \mathrm{di-}$ mensions (from the faces of the lining) are $6.5 \mathrm{~m} \times 3.6 \mathrm{~m}$ $\times 3.0 \mathrm{~m}$ (vertical). A miniature $(0.1 \mathrm{~m}$ diameter $)$ dodecahedral loudspeaker (type Dr Three) was used as the source. This loudspeaker qualifies as omnidirectional according to ISO3382-1 ${ }^{18}$ criteria over the measurement 


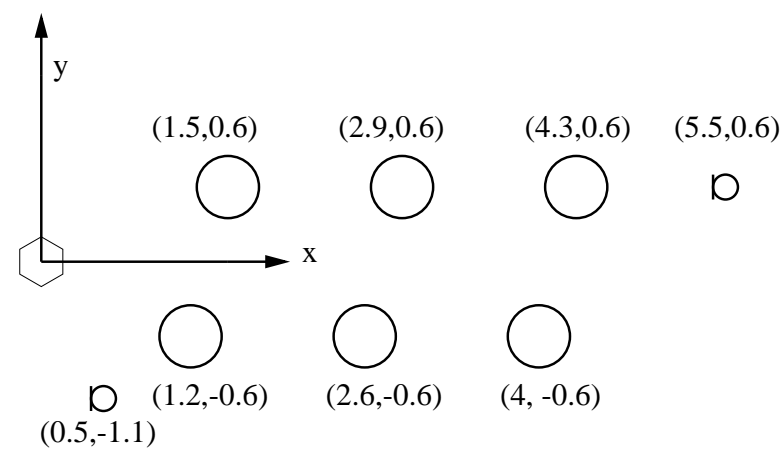

FIG. 1. Setup of seated musicians in the hemi-anechoic chamber. The coordinates (in $\mathrm{m}$ ) specified for each musician refer to the centre of the back of the musician's chair. The source was located at the origin of the coordinate system. Also shown are the $5.5 \mathrm{~m}$ microphone and the reference microphone. The same configuration was used for standing musicians, however in that case the coordinates refer to the approximate centre point of each standing musician. The source and receiver heights were respectively $0.8 \mathrm{~m}$ and $1.2 \mathrm{~m}$ for seated tests, and $1.0 \mathrm{~m}$ and $1.5 \mathrm{~m}$ for standing tests.

frequency range, with deviations within $\pm 1 \mathrm{~dB}$ up to the $2 \mathrm{kHz} 1 / 3$-octave band. The receivers were omnidirectional microphones $(1 / 2$ inch diameter Brüel\&Kjær type 4190). The difference in sound pressure level (SPL) between the $5.5 \mathrm{~m}$ microphone and reference microphone was investigated. Both the seated and standing musicians were modeled in Autodesk Inventor $\AA$ using combinations of simple geometries to allow for easy meshing.

\section{B. Orchestra impedance values and agreement between full scale measurements and BEM model}

For the BEM model of the chamber orchestra separate impedance values were applied to musicians and music stands. To specify impedance values for musicians the equivalent absorption areas selected by Dammerud and Barron ${ }^{3}$ for their scale model were first considered. Dammerud and Barron measured these equivalent absorption areas for the model musicians in a scale reverberation chamber, and matched them as closely as possible to the full scale absorption areas for musicians measured in a full sized reverberation chamber by Harwood et al. ${ }^{16}$. A quadratic curve was fitted to these data for absorption area $(A)$ versus frequency, so that the impedance values were gradually changed with frequency. Then the equivalent absorption areas were related to an absorption coefficient by dividing by the object surface area. The seated and standing model musicians have an approximate surface area of $2 \mathrm{~m}^{2}$ each. This relationship is only strictly valid when the absorption coefficient of a large flat sample of a material is being measured in a reverberation chamber. Although Dammerud and Barron measured absorption area in a reverberation chamber, model musicians were three-dimensional hence the use of this data to obtain absorption coefficients is approximate, however use of these values was validated in a sensitivity analysis described shortly, which found that results were insensitive to the impedance values specified. The absorption coefficients were then converted to impedance values. Equivalent absorbing area (or the corresponding absorption coefficients) only provide information regarding the change in amplitude of the sound wave once reflected by the object, not the change in phase. The reflection coefficient was assumed to be positive and real (i.e. $R=\sqrt{1-\alpha}$ ). An imaginary component of the reflection coefficient implies some change in phase - significant phase change generally only occurs when the absorbing layer is thick compared with the wavelength, or has an air gap behind it (which may be the case for clothing in some cases). However, in the absence of a rational basis for defining an imaginary part of the complex impedance it was set to zero. Table I summarizes the absorption area per musician from Dammerud and Barron's scale model, the equivalent absorption coefficients, and the corresponding reflection factor magnitude and complex impedance.

As well as the seated musicians, impedance values had to be applied to music stands. Absorption coefficients based on $1 \mathrm{~cm}$ thick plywood taken from Cox and D'Antonio $^{19}$, see Table II. Similar to the case of the musicians, these absorption coefficients are approximate. However, the shortly described sensitivity analysis finds the geometry itself rather than the impedance applied is more critical over the frequency range $125-1000 \mathrm{~Hz}$ octaves meaning the impedance specified to the music stands is not important. Again, the reflection coefficient $(R)$ was assumed to be real and positive, and this time an exponential curve was a better fit to $\alpha$ to avoid jumps in $\Delta L$ due to an abrupt change in impedance in each octave band. The music stands were modeled as just the music stand face, without a 'pole', because the slender pole would require a fine mesh (and large number of elements) to model but would not significantly impact the sound fields under $2000 \mathrm{~Hz}$. Music stands are not included in the validation setup (Section II A), however they are included in the final chamber orchestra model (Section III A).

Impedance values up to $2000 \mathrm{~Hz}$ were defined for the purposes of curve fitting, although computations were only conducted up to the upper end of the $1000 \mathrm{~Hz}$ octave since the next octave required a four-fold element number increase and was not feasible for the final orchestra model.

To compare the results from the full scale measurements and the BEM model a quantity $\Delta L_{5.5 \mathrm{~m} \text { - ref was }}$ defined as the difference in SPL between the $5.5 \mathrm{~m}$ receiver and the reference receiver, see Eq. 1. The precise receiver locations for the these receivers are shown in Figure 1. 
TABLE I. Absorption area, absorption coefficients, corresponding reflection coefficients and impedance values applied to surfaces of seated musicians based on Dammerud and Barron's absorption areas.

\begin{tabular}{l|lllll}
\hline \hline Octave $(\mathrm{Hz})$ & 125 & 250 & 500 & 1000 & 2000 \\
\hline $\mathrm{A}\left(\mathrm{m}^{2}\right)$ & 0.07 & 0.24 & 0.41 & 0.7 & 0.86 \\
$\alpha$ & 0.03 & 0.12 & 0.2 & 0.35 & 0.43 \\
$|R|$ & 0.98 & 0.94 & 0.89 & 0.81 & 0.76 \\
$Z_{s}\left(\mathrm{~kg} / \mathrm{m}^{2} \mathrm{~s}\right)$ & 46547 & 12981 & 7241 & 3870 & 2975 \\
\hline \hline
\end{tabular}

$$
\Delta L_{5.5 \mathrm{~m}-\mathrm{ref}}=\mathrm{SPL}_{5.5 \mathrm{~m}}-\mathrm{SPL}_{\mathrm{ref}}
$$

Before considering the agreement between full scale and BEM results, the sensitivity analysis conducted for the impedance values of the chamber orchestra model used in this work will be described. Increasing or decreasing the absorption coefficient by 0.1 from those used in Table I (subject to the constraint that $\alpha \geq 0$ ) resulted in

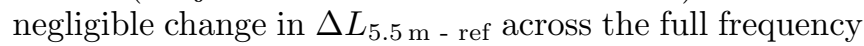
range (125-1000 $\mathrm{Hz}$ octave bands), which indicated insensitivity to the exact choice of absorption applied to the musicians, as shown in Figure 2 c. In cases where absorption coefficient could not be reduced by 0.1 (for example $125 \mathrm{~Hz}$ octave band) the perfectly reflective case was examined. The insensitivity to absorption coefficient

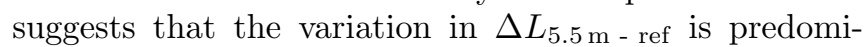
nantly due to wave diffraction around the orchestra. This is unsurprising given that the wavelengths investigated $(240 \mathrm{~mm}$ to $1.9 \mathrm{~m})$ range from typical small scale feature dimension of the geometry to typical spacings between musicians.

Now the agreement between full scale measurement and BEM results is discussed. When considering oc-

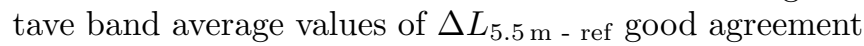
was found between the BEM model and the full scale measurements for both the seated and standing musician configurations. The results from the BEM model between $125-1000 \mathrm{~Hz}$ octave bands are within generally $\pm 2 \mathrm{~dB}$ of the full scale measurement results. Examining

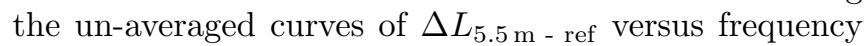
demonstrates that the BEM model also captures most of the smaller changes with frequency observed in the curves from the full scale measurements, see Figure 2. The results in Figure 2 are for a source height of $0.8 \mathrm{~m}$ for the seated musician case, and a source height of $1.2 \mathrm{~m}$ for the standing musician case. In a few places sharp dips

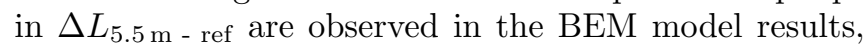
which are not seen as strongly in the full scale measurement results. This indicates some destructive interference occurring in the BEM model, which did not occur in full scale measurements. This is likely because in the case of the full scale measurements no two musicians geometries were truly identical, whereas in the BEM model the geometry of each musician is identical and they are
TABLE II. Absorption coefficients and corresponding impedance values applied to music stands.

\begin{tabular}{cccccc}
\hline \hline Octave $(\mathrm{Hz})$ & 125 & 250 & 500 & 1000 & 2000 \\
\hline$\alpha$ & 0.28 & 0.22 & 0.17 & 0.09 & 0.10 \\
$|R|$ & 0.85 & 0.88 & 0.91 & 0.95 & 0.95 \\
$Z_{s}\left(\mathrm{~kg} / \mathrm{m}^{2} \mathrm{~s}\right)$ & 5026 & 6639 & 8848 & 17471 & 15640 \\
\hline \hline
\end{tabular}

spaced exactly evenly between the source and receiver. The physical measurements therefore tend to have wider but shallower dips and after averaging the difference is small. A source height of $1.0 \mathrm{~m}$ for the seated musician case, and source height of $1.5 \mathrm{~m}$ for the standing musician case were also examined with similar agreement observed.

This validation study found that good agreement was achieved between the BEM model and full scale results with both sitting and standing subjects. Based on this agreement it can be concluded that at and below the $1 \mathrm{kHz}$ octave band the simplified musician geometries are satisfactory; clearly the presence of large geometries impacts the sound field over this frequency range, while the finer details do not. Throughout the validation process it was found that diffraction is dominant and results are generally insensitive to $\alpha$. Based on these findings instrument geometries will be included in the final orchestra model, but applied with same impedance as the musicians.

\section{BEM MODEL OF A CHAMBER ORCHESTRA}

\section{A. Introduction}

The final chamber orchestra model with instrument geometries included is shown in Figure ??. The inner-most circle of musicians has a radius of $2 \mathrm{~m}$ and the outer circle of musicians has a radius of $3.2 \mathrm{~m}$. Music stands are located $0.8 \mathrm{~m}$ forward of musicians' heads at a height of approximately $1.2 \mathrm{~m}$ (to the base of the stand) for standing musicians and approximately $0.75 \mathrm{~m}$ (to the base of the stand) for seated musicians, with each stand shared between two players in accordance with usual practice. In the BEM model omnidirectional source and omnidirectional receivers were simulated. Additionally, a perfectly reflective stage floor was represented with a symmetry plane.

$\mathrm{T}$

For on-stage measurements, Gade ${ }^{6}$ has suggested removing all stage furniture within a $2 \mathrm{~m}$ radius of the source and receiver to avoid significant influence from the nearby objects on acoustic measurements. For a chamber orchestra on stage a $2 \mathrm{~m}$ radius around both the source and receiver would equate to removing almost all the onstage objects. For smaller stages (such as those which may be unsuitable for a symphony orchestra but used by 
(a)

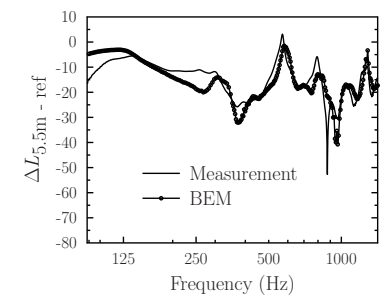

(b)

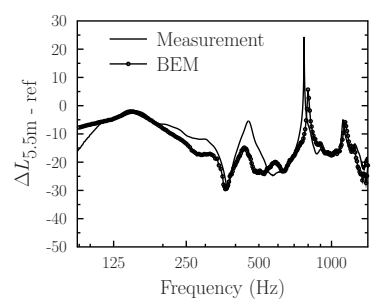

$(c)$

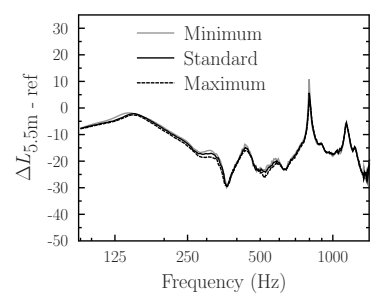

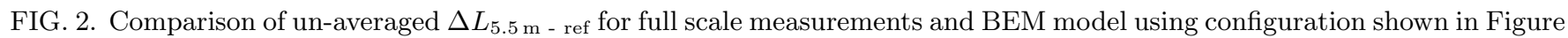

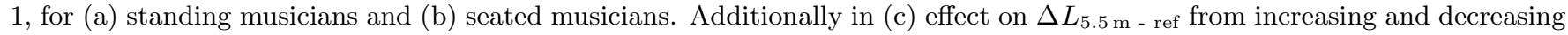
absorption coefficient by 0.1 for BEM model of seated musicians arranged in configuration shown in Figure 1 . Minimum refers to the lowest absorption coefficient tried, maximum refers to the highest absorption coefficient tried and standard refers to the absorption coefficients provided in Table I, and used in all later investigations.

a chamber orchestra), Gade suggests empty stage measurements.

The aim of this paper is to consider how representative unoccupied stage measurements are for a chamber sized orchestra. The approach in this paper was therefore to clear any objects that have any part within a radius of $0.5 \mathrm{~m}$ so that most of the orchestra would remain. The cleared radius of $0.5 \mathrm{~m}$ generally equated to the musician at the source or receiver location and in some cases the nearest music stand. This left a reasonably realistic onstage setup, and this is in line with the method used by others when investigating the impact of an orchestra on on-stage sound fields ${ }^{3,5}$.

\section{B. Effect of stage objects on direct sound and floor reflection: results and discussion}

In this section the attenuation of the direct sound and floor reflection and the contribution of early reflections from nearby stage objects are investigated using the validated BEM model. Several cases are presented with various source and receiver locations within the chamber orchestra. The source and receiver locations have been selected as player locations, both at $1.5 \mathrm{~m}$ above the stage floor. For this analysis a quantity $\Delta L$ is defined as the SPL at the receiver relative to the SPL of the direct sound only (in the absence of any orchestra or floor) at the same receiver location. As such,

$$
\Delta L=\mathrm{SPL}_{\text {receiver }}-\mathrm{SPL}_{\text {direct }}
$$

where $\mathrm{SPL}_{\text {receiver }}$ is the SPL at a receiver on stage and $\mathrm{SPL}_{\text {direct }}$ is the 'free field' direct SPL at the same receiver location (as used by Dammerud and Barron ${ }^{3}$ to investigate on-stage sound fields for symphony orchestras).

The results denoted as 'Analytic' in the following sections have been computed from direct sound and floor reflection (i.e. the empty stage solution), which will have a limiting value of $+6 \mathrm{~dB}$ when these two are in phase and of equal amplitude.

Three different source-receiver cases have been consid- ered, as shown in Figure 3. For Case 1 the attenuation between two players across roughly the geometric center of the orchestra is investigated, for Case 2 the attenuation between the left-most player in the orchestra and the right-most player in the orchestra is investigated and for Case 3 the attenuation between the concertmaster (i.e. principal first violin) and a back row player in the orchestra is investigated. The empty stage (Analytic) and occupied stage (BEM) solutions are shown for Case 2 in Figure 4 over the full frequency range; the same results are not presented for Cases 1 and 3 but were similar, although Case 3 generally showed less attenuation across the full frequency range than the other two cases.

From the un-averaged curve of $\Delta L$ versus frequency (Figure 4) it is evident that there is general agreement between the empty stage (Analytic) and BEM solution in terms of gross features. However, dips due to destructive interference may be frequency shifted and have different magnitudes - this is due to the modified path lengths because of the presence of the chamber orchestra and to a small extent the surface absorption of the musicians. Additional dips and peaks also arise from a proliferation of multiple sound paths.

The differences after octave band averaging between the Analytic case (empty stage) and the BEM case (occupied stage) are presented in Table III. Case 1 shows low attenuation at the $125 \mathrm{~Hz}$ and $250 \mathrm{~Hz}$ octave bands, but significant attenuation of the direct sound and floor reflection for $500 \mathrm{~Hz}$ and $1000 \mathrm{~Hz}$ octave bands. Case 2 shows significant effect of stage objects at all frequencies above the $125 \mathrm{~Hz}$ octave band. Notably the value of $\Delta L$ is positive at $250 \mathrm{~Hz}$ indicating that the SPL on the empty stage at the receiver location is actually lower than on the occupied stage. From Figure 4 we can see that this is because for the occupied stage solution the destructive interference between the direct sound and floor reflection is significantly reduced and the constructive interference at higher frequencies is shifted into the $250 \mathrm{~Hz}$ octave band. Case 3 shows minimal effect from stage objects across the whole frequency range of interest, with the exception of the $250 \mathrm{~Hz}$ octave band. 
(a)

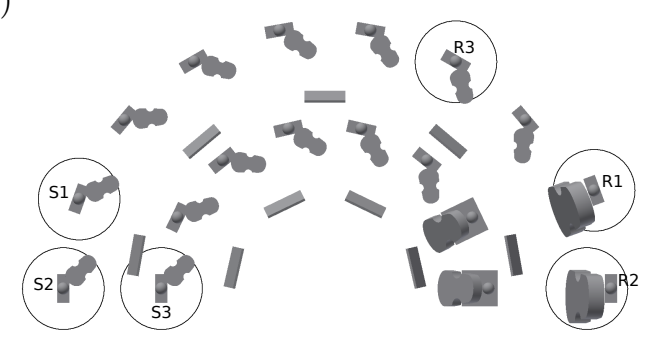

FIG. 3. The source-receiver locations for the three cases investigated, (a) Case 1 with source-receiver distance of $6.3 \mathrm{~m}$, (b) Case 2 with source-receiver distance of $6.4 \mathrm{~m}$ and (c) Case 3 with source-receiver distance of $4.5 \mathrm{~m}$.

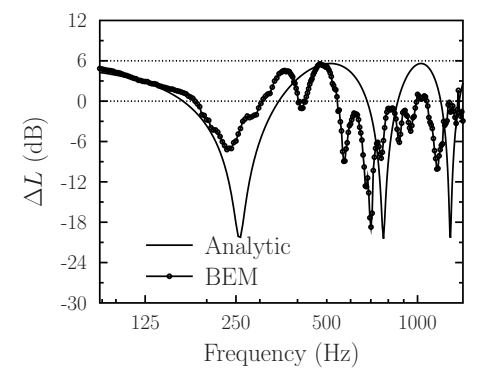

FIG. 4. Case 2 orchestra configuration and sound field results for direct sound and floor reflection only. $\Delta L$ versus frequency (direct sound and floor reflection only) (Analytic = empty stage, $\mathrm{BEM}=$ occupied stage)

\section{Effect of stage objects on first-order reflections: results and discussion}

In this section the effect of the chamber orchestra on first-order reflections from the stage enclosure is investigated. The mesh required to implement a stage enclosure in the BEM model would be too large for the model to be feasible to solve. Instead walls and ceiling have been modeled one at a time using symmetry, by creating an image of the orchestra and adjusting the omnidirectional source location in the BEM model appropriately. An example of the setup for investigating the left stage wall first-order reflection for the typical enclosure

TABLE III. Difference between octave band average values of BEM $\Delta L$ and Analytic $\Delta L(\mathrm{~dB})$ for direct sound and floor reflection only for the three orchestra configurations investigated (Cases 1, 2 and 3).

\begin{tabular}{cccc}
\hline \hline Octave $(\mathrm{Hz})$ & Case 1 & Case 2 & Case 3 \\
\hline 125 & 0.1 & 0.5 & -0.1 \\
250 & -0.8 & 3.9 & -2.8 \\
500 & -6.0 & -2.6 & -1.8 \\
1000 & -6.0 & -4.0 & -0.5 \\
\hline \hline
\end{tabular}
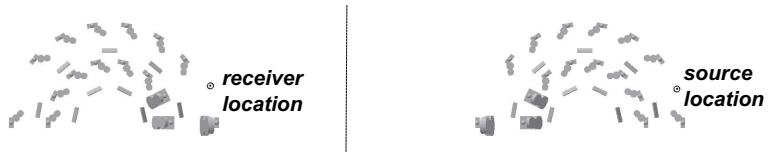

FIG. 5. The setup used to investigate the left wall reflection for Case 1. The left wall reflection has been investigated by creating a mirror image of the orchestra, and the source has been moved as shown (receiver location is unchanged from direct sound investigation). The dashed line is the left wall.

is shown in Figure 5 in which the orchestra is mirrored about the left enclosure wall. The receiver location remains unchanged from that used in the investigation of the direct sound, but the source is moved to the image to give the correct source-receiver geometry for the left wall first-order stage reflection. The source used to investigate the direct sound is removed in this analysis, so the stage enclosure reflection attenuation can be considered separately. 'Left', 'right' and 'back' in this paper are defined from the perspective of a musician on stage facing the audience. This method has the advantage of allowing the first-order stage enclosure reflections to be studied individually, which is of interest because physical measurements are generally studied as impulse responses, and further because complementary work involving stage measurements in auditoria assessed by chamber orchestras has included analysis of both the spatial and temporal response ${ }^{14}$.

The specific effect of stage objects on higher order reflections (and subsequently on-stage acoustic measures) will depend on the stage enclosure size and shape. Two stage enclosures sizes have been investigated. The dimensions of the first stage enclosure are $15.5 \mathrm{~m}$ wide and $8 \mathrm{~m}$ deep and $12 \mathrm{~m}$ high (height of ceiling above stage), which are typical of purpose-built concert hall stages that are included in the subjective and objective survey of stage acoustics for chamber orchestras ${ }^{14}$, and this stage enclosure will be referred to as the 'typical' enclosure size. Also, a 'small' stage enclosure has been investigated, the dimensions of which are $11.4 \mathrm{~m}$ wide, $6 \mathrm{~m}$ deep and $9 \mathrm{~m}$ high. The dimensions of the 'small' enclosure were chosen to agree with the stage enclosure size used in the full scale measurements with a chamber orchestra in an auditorium presented in Section IV.

In this section the attenuation of first-order reflections for the typical and small enclosures is investigated. The arrival times for first-order reflections (relative to the direct sound) for source-receiver locations in Cases 1, 2 and 3 are shown in Figure 6 for the typical and small enclosures. First-order reflections, and the corresponding floor reflection, are included in the BEM analysis, but no other second order reflections are considered.

The results for difference between BEM and Analytic for the first-order reflections for Cases 1,2 and 3 are summarized in Table IV for the typical and small enclosures. To illustrate typical detail $\Delta L$ is plotted against frequency for each first-order reflection for Case 1 with 
(a)

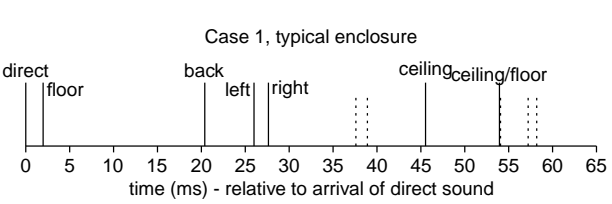

(b)

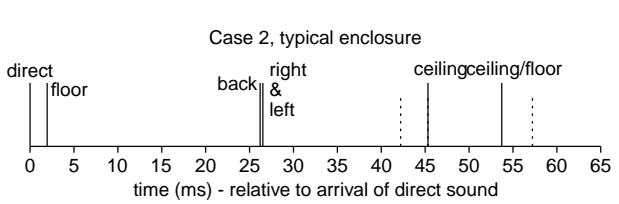

(c)

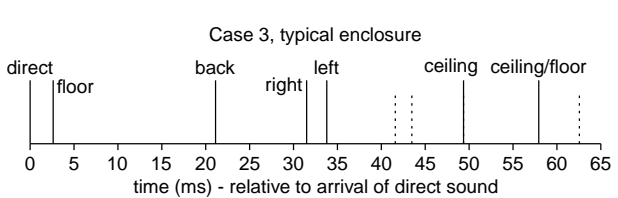

$(d)$

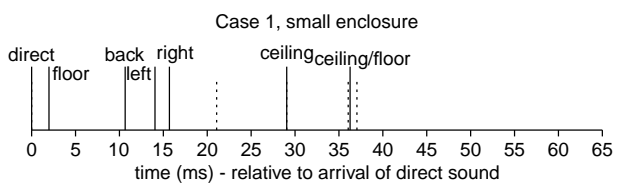

(e)

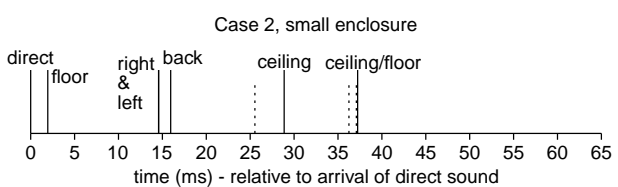

$(f)$

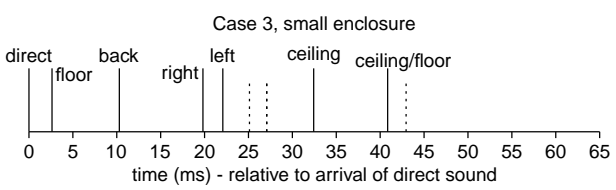

FIG. 6. Arrival of first-order reflections (relative to arrival of direct sound) for typical and small stage enclosure, with source and receiver locations as used in Cases 1,2 and 3. The first-order reflections are shown with a solid line, and initial second-order reflections (not accounted for in BEM model) are shown with a dashed line. Each first-order reflection is also closely followed by a floor reflection (not shown), with the exception of reflection via ceiling and floor which is shown as this is more widely spaced and is the final reflection accounted for in the BEM model. Each figure is labeled with the enclosure size and case number.

the typical enclosure in Figure 7. $\Delta L$ is defined in the same manner as in Section III B as the difference between the SPL at the receiver and the SPL at the same sourcereceiver distance in a free field.

In all cases the ceiling reflection is not significantly affected by the presence of the orchestra at any frequency. This result is expected because the ceiling reflection path does not pass through the orchestra when traveling from source to receiver, and thus would only be minimally impacted by some reflections from nearby stage objects.

For Case 1 typical enclosure, there is minimal difference in first-order reflection with and without the orchestra in the $125 \mathrm{~Hz}$ octave. However, there is notable attenuation for the $1000 \mathrm{~Hz}$ octave band for all the firstorder reflections (as high as $6 \mathrm{~dB}$ ), with the exception of the ceiling reflection. For the intermediate octave bands $(250 \mathrm{~Hz}$ and $500 \mathrm{~Hz})$ the effect is varied. The similarity for $250 \mathrm{~Hz}$ and $500 \mathrm{~Hz}$ between the empty and occupied stage solutions is dependent on how the destructive interference between the direct sound and floor reflection is altered by the presence of the stage objects. For Cases 2 and 3 , the findings are very similar to Case 1 , with high attenuation at the $1000 \mathrm{~Hz}$ octave band, varied levels of attenuation at $250 \mathrm{~Hz}$ and $500 \mathrm{~Hz}$, and minimal attenuation for the $125 \mathrm{~Hz}$ octave.

Regarding the small enclosure size, again none of the first-order reflections are attenuated by more than $1 \mathrm{~dB}$ at the $125 \mathrm{~Hz}$ octave band, and there is minimal difference in occupied and empty stage solutions for the unobstructed ceiling reflection. Again for this enclosure size there is generally high attenuation in the $1000 \mathrm{~Hz}$ octave band and varied levels of attenuation at $250 \mathrm{~Hz}$ and $500 \mathrm{~Hz}$.

The first-order reflections are combined to give a 'Stage Walls Combined' (SWC) quantity. In Table IV the difference between occupied and empty SWC is given and this

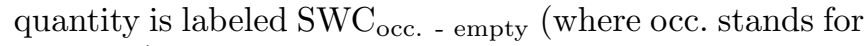
occupied). The definition of this quantity is

$$
\mathrm{SWC}_{\text {occ. - empty }}=10 \log _{10}\left(\frac{\left(\sum p_{i}^{2}\right)_{\mathrm{BEM}}}{\left(\sum p_{i}^{2}\right)_{\text {Analytic }}}\right)
$$

where $p_{i}=p_{\text {direct }}, p_{\text {back }}, p_{\text {left }}, p_{\text {right }}$ and $p_{\text {ceiling }}$ and are the pressures from direct sound, back wall, left wall, right wall and the ceiling respectively. Note, the direct sound and each first-order reflection includes the corresponding floor reflection, since a symmetry plane was in place to represent the floor. It should also be noted that the square of the pressure magnitude was summed (rather than complex pressures being added before squaring their resultant magnitude) because in the auditorium used for validation (see Section IV) the ornate surfaces would produce some spatial and temporal diffusion, thus the reflections would behave as incoherent sources, not perfectly coherent sources. However, the floor reflection will be coherent since the floor is perfectly flat and rigid, and this is accounted for by including the floor reflection in the BEM model (with use of a symmetry plane). This method gives good agreement with the auditorium measurements presented in Section IV. The pressure squared sum method is therefore also used for the 'typical' enclosure BEM results since most auditoria would have similarly diffusing walls and a flat floor. Also included in

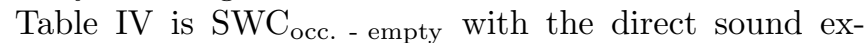
cluded. Direct sound is excluded in some common stage parameters, such as $S T_{\text {early }}$ where the early is defined as $20-100 \mathrm{~ms}^{6}, L Q_{7-40}$ where early is defined as $7-40 \mathrm{~ms}^{7}$ and a variation on early support $S T_{\text {early,d }}$ where $10 \mathrm{~ms}$ is used instead of $20 \mathrm{~ms}$ to start the early time interval ${ }^{8}$. Direct sound is also included in some stage parameters, such as $G_{0-80}$ where early is defined as $0-80 \mathrm{~ms}^{1}$.

Figure 6 suggests that for the typical stage enclosure, 
(a)

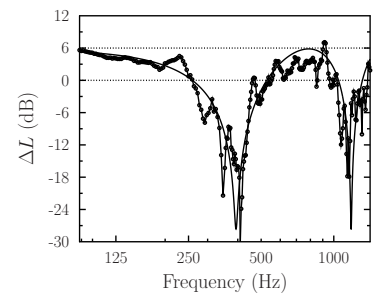

(c)

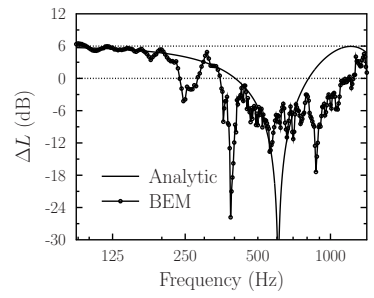

(b)

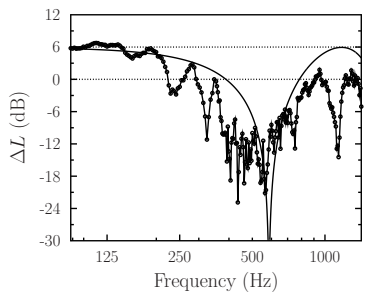

$(d)$

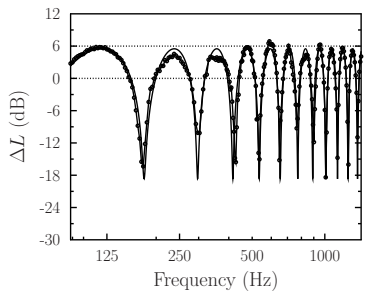

FIG. 7. $\Delta L$ versus frequency for Analytic and BEM solution for Case 1 first-order reflections for the typical stage enclosure (Analytic = empty stage, BEM = occupied stage); (a) back wall reflection, (b) left wall reflection, (c) right wall reflection and $(\mathrm{d})$ ceiling reflection.

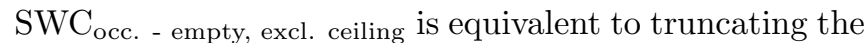
signal at around $40 \mathrm{~ms}$, while $\mathrm{SWC}_{\text {occ. - empty, incl. ceiling }}$ is equivalent to truncating the signal at around $60 \mathrm{~ms}$; however, it should be noted there would generally be second order stage enclosure reflections occurring before the ceiling, which were not considered in the BEM model.

\section{Effect of stage objects for varying reflection arrival elevation angle}

This section considers the effect of the chamber orchestra on lateral reflections arriving at angles between the horizontal and vertical plane, such as those caused by an angled reflector or angled side wall. The source and receiver locations were those of Case 1, and angled left wall reflections were considered (where $\theta$ is the angle the left side wall is tilted from vertical), as shown in Figure 8. The angle $\theta$ was varied from $0^{\circ}$ (left wall reflection case for standard enclosure size as presented in Section III C) to $40^{\circ}$, and the equivalent source-receiver distance was kept constant (at $15.2 \mathrm{~m}$ ), thus reflection surfaces were tangent to a common ellipse. The results are graphed in Figure 9, where difference between BEM and Analytic (i.e. occupied and empty) is plotted against $\theta$.

The effect of the orchestra reduces rapidly with increasing angle $\theta$ for 500 and $1000 \mathrm{~Hz}$ octave bands, as the primary source-receiver path progressively clears the orchestra. $\Delta L$ approaches $0 \mathrm{~dB}$, which is not surprising as this is the result for the ceiling reflection (effectively $\theta=90^{\circ}$, albeit with a different source-receiver distance).

The effect on the other hand is relatively independent of angle for 125 and $250 \mathrm{~Hz}$ bands. These frequencies

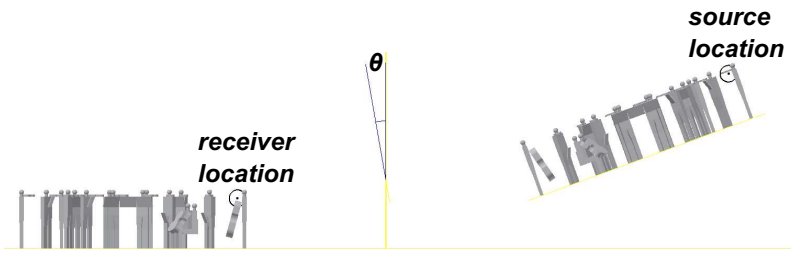

FIG. 8. Angled chamber orchestra model as modeled in Autodesk Inventor, for angle $\theta=10^{\circ}$.

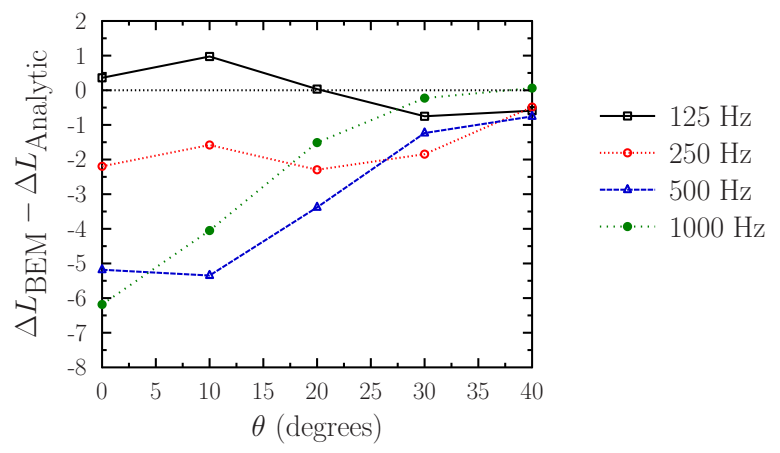

FIG. 9. (Color online) $\Delta L_{\mathrm{BEM}}-\Delta L_{\text {Analytic }}$ as a function of angle $\theta$ (as defined in Figure 8) for $125-1000 \mathrm{~Hz}$ octave bands.

have already been shown to be relatively unaffected by the orchestra. Interestingly the $250 \mathrm{~Hz}$ octave is consistently lower than the $125 \mathrm{~Hz}$ octave, a result also seen in Table IV. This may be due to additional interference from the proliferation of paths in the vicinity of the first destructive interference.

\section{FULL SCALE MEASUREMENTS IN AN AUDITORIUM WITH A CHAMBER ORCHESTRA}

\section{A. Introduction}

To further validate the use of BEM to model a chamber orchestra, and the use of symmetry in the BEM model to replicate first-order stage enclosure reflections, full scale measurements were undertaken in an auditorium with a chamber orchestra (including music stands, seats, instruments and the musicians themselves). For the auditorium measurements a Brüel\&Kjær omnidirectional loudspeaker type 4295 was used, along with an amplifier (Brüel\&Kjær power amplifier type 2734) and computer software with an audio interface (AARAE release 7 with Fireface UCX interface). An exponential sweep with duration $30 \mathrm{~s}$, start frequency $50 \mathrm{~Hz}$ and end frequency $20 \mathrm{kHz}$ was used in impulse response measurements, and the receiver used was a Brüel\&Kjær omnidirectional microphone type 4910 .

The auditorium used for these measurements was the Hobart Town Hall (Tasmania, Australia). Due to the 
TABLE IV. Difference between octave band average values of BEM $\Delta L(\mathrm{~dB})$ and Analytic $\Delta L(\mathrm{~dB})$ for Cases 1,2 and 3 , for

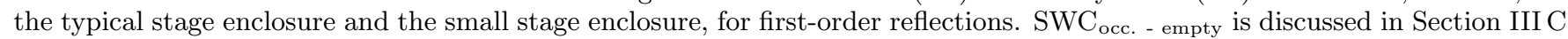
and is defined in Eq. 3.

\begin{tabular}{|c|c|c|c|c|c|c|c|c|c|}
\hline \multirow[t]{2}{*}{$\overline{\text { Case }}$} & \multirow[b]{2}{*}{ Octave $(\mathrm{Hz})$} & \multicolumn{4}{|c|}{ Typical } & \multicolumn{4}{|c|}{ Small } \\
\hline & & 125 & 250 & 500 & 1000 & 125 & 250 & 500 & 1000 \\
\hline \multirow{8}{*}{1} & Direct (and floor) & 0.2 & -0.8 & -6.0 & -6.0 & 0.2 & -0.8 & -6.0 & -6.0 \\
\hline & Back Wall & -0.4 & 0.4 & -1.2 & -1.9 & -0.8 & 0.5 & -0.2 & -4.7 \\
\hline & Right Wall & 0.1 & -1.3 & -2.5 & -5.2 & -0.1 & -2.2 & -2.3 & -5.2 \\
\hline & Left Wall & 0.4 & -2.2 & -5.2 & -6.2 & 0.1 & -2.7 & -4.8 & -5.9 \\
\hline & Ceiling & 0.1 & -0.8 & 0.3 & -0.2 & 0.1 & -0.8 & -0.2 & -0.2 \\
\hline & $\mathrm{SWC}_{\text {occ. - empty, excl. ceiling }}$ & 0.0 & -0.9 & -4.7 & -4.6 & -0.1 & -1.2 & -4.1 & -5.5 \\
\hline & (exclude direct) & $(-0.1)$ & $(-0.9)$ & $(-1.6)$ & $(-3.6)$ & $(-0.3)$ & $(-1.3)$ & $(-1.4)$ & $(-5.2)$ \\
\hline & $\begin{array}{l}\mathrm{SWC}_{\text {occ. - empty, incl. ceiling }} \\
\text { (exclude direct) }\end{array}$ & $\begin{array}{c}0.0 \\
(0.0)\end{array}$ & $\begin{array}{l}-0.9 \\
(-0.9)\end{array}$ & $\begin{array}{l}-4.3 \\
(-1.2)\end{array}$ & $\begin{array}{l}-4.3 \\
(-3.2)\end{array}$ & $\begin{array}{l}-0.1 \\
(-0.2)\end{array}$ & $\begin{array}{l}-1.1 \\
(-1.2)\end{array}$ & $\begin{array}{l}-3.7 \\
(-1.1)\end{array}$ & $\begin{array}{l}-4.8 \\
(4.2)\end{array}$ \\
\hline \multirow{8}{*}{2} & Direct (and floor) & 0.5 & 3.9 & -2.6 & -4.0 & 0.5 & 3.9 & -2.6 & -4.0 \\
\hline & Back Wall & -0.5 & -1.5 & -3.3 & -3.8 & -0.8 & -3.8 & -2.0 & -3.7 \\
\hline & Right Wall & 0.2 & -2.3 & 0.3 & -3.3 & 0.1 & -1.6 & -0.7 & -2.3 \\
\hline & Left Wall & 0.5 & -1.2 & -1.9 & -4.6 & 0.3 & -1.4 & -2.8 & -5.3 \\
\hline & Ceiling & 0.1 & -0.7 & -0.5 & -0.1 & 0.1 & -0.3 & -0.4 & -0.2 \\
\hline & $\mathrm{SWC}_{\text {occ. - empty, excl. ceiling }}$ & 0.3 & 0.4 & -2.5 & -3.9 & 0.1 & 0.0 & -2.4 & -3.8 \\
\hline & (exclude direct) & $(0.1)$ & $(-1.7)$ & $(-1.4)$ & $(-3.9)$ & $(-0.1)$ & $(-2.1)$ & $(-1.7)$ & $(-3.6)$ \\
\hline & $\begin{array}{l}\mathrm{SWC}_{\text {occ. - empty, incl. ceiling }} \\
\text { (exclude direct) }\end{array}$ & $\begin{array}{c}0.3 \\
(0.1)\end{array}$ & $\begin{array}{c}0.3 \\
(-1.5)\end{array}$ & $\begin{array}{l}-2.3 \\
(-1.0)\end{array}$ & $\begin{array}{l}-3.6 \\
(-3.3)\end{array}$ & $\begin{array}{c}0.1 \\
(-0.1)\end{array}$ & $\begin{array}{c}0.0 \\
(-1.8)\end{array}$ & $\begin{array}{l}-2.2 \\
(-1.3)\end{array}$ & $\begin{array}{l}-3.4 \\
(-3.0)\end{array}$ \\
\hline \multirow{8}{*}{3} & Direct (and floor) & -0.1 & -2.8 & -1.8 & -0.5 & -0.1 & -2.8 & -1.8 & -0.5 \\
\hline & Back Wall & -0.6 & -0.3 & 1.0 & -3.7 & -0.9 & -0.6 & -2.2 & -2.0 \\
\hline & Right Wall & -0.6 & -0.2 & -3.5 & -3.8 & 0.0 & -1.0 & -3.6 & -1.5 \\
\hline & Left Wall & 0.00 & -1.4 & -3.6 & -3.9 & -0.9 & -0.8 & -2.5 & -3.2 \\
\hline & Ceiling & -0.4 & 0.1 & 0.0 & -0.4 & -0.6 & 0.00 & -0.9 & -0.1 \\
\hline & $\mathrm{SWC}_{\text {occ. - empty, excl. ceiling }}$ & -0.3 & -2.0 & -1.6 & -1.3 & -0.4 & -2.1 & -2.4 & -1.2 \\
\hline & (exclude direct) & $(-0.5)$ & $(-0.7)$ & $(-0.2)$ & $(-3.8)$ & $(-0.5)$ & $(-0.8)$ & $(-3.0)$ & $(-2.0)$ \\
\hline & $\begin{array}{l}\text { SWC }_{\text {occ. - empty, incl. ceiling }} \\
\text { (exclude direct) }\end{array}$ & $\begin{array}{l}-0.3 \\
(-0.4)\end{array}$ & $\begin{array}{l}-1.9 \\
(-0.5)\end{array}$ & $\begin{array}{l}-1.6 \\
(-0.2)\end{array}$ & $\begin{array}{l}-1.2 \\
(-3.3)\end{array}$ & $\begin{array}{l}-0.4 \\
(-0.5)\end{array}$ & $\begin{array}{l}-1.9 \\
(-0.6)\end{array}$ & $\begin{array}{l}-2.4 \\
(-2.8)\end{array}$ & $\begin{array}{l}-1.1 \\
(-1.8)\end{array}$ \\
\hline
\end{tabular}

small stage size, the orchestra was set up at the back of the auditorium, which provided an approximate 'shoebox' stage enclosure with ceiling height of $9.0 \mathrm{~m}$, stage width of $11.4 \mathrm{~m}$, stage depth of $6.0 \mathrm{~m}$ (from the front of the ensemble). The source and receiver were both at a height of $1.5 \mathrm{~m}$. Figure 10 shows the chamber orchestra in situ in the auditorium. It should be noted that the interior plaster surfaces of the auditorium were quite ornate, and included various sized and shaped alcoves, and these details were not included in the BEM model, and would result in significantly more scattering, rather than discrete reflections.

The same source-receiver configurations used in the BEM model (Cases 1,2 and 3) were also investigated in the auditorium measurements. Three identical measurements were conducted for each case, between which the orchestra was asked to relax and move around to deliberately introduce small random perturbations to the orchestra configuration. Measurements were also taken on stage with no orchestra present (empty stage), for Cases 1, 2 and 3, for comparison to the occupied stage measurements.

These full scale measurements also had several advan-

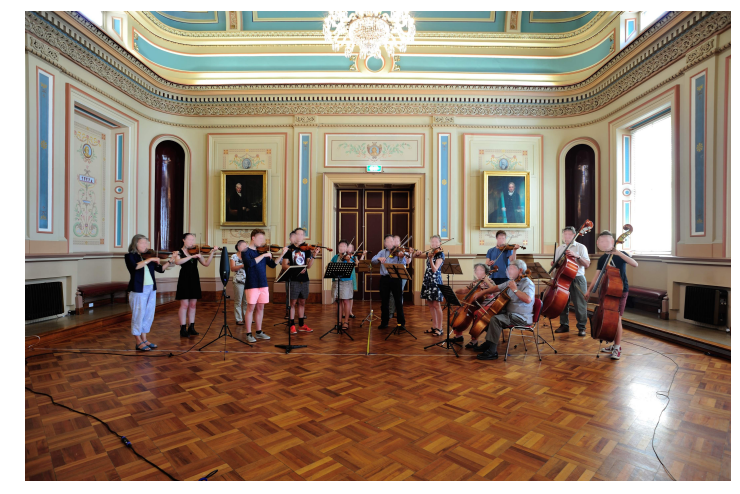

FIG. 10. (Color online) The chamber orchestra setup in the auditorium.

tages over the BEM model: higher frequencies could be investigated which are not possible with the BEM model, and higher order reflections could also be considered, where the BEM model investigation was limited to only the first-order stage enclosure reflections. 


\section{B. Auditorium measurements with a chamber orchestra: results and discussion}

To investigate the equivalent quantity considered with the BEM model (Eq. 3), the occupied and empty stage measurements were compared using $\mathrm{SWC}_{\text {occ. }}$ - empty defined as

$$
\mathrm{SWC}_{\text {occ. }- \text { empty }}=10 \log _{10}\left(p_{\text {occupied }}\right)^{2}-10 \log _{10}\left(p_{\text {empty }}\right)^{2} \text {, }
$$

where $p_{\text {occupied }}$ is the pressure at the receiver with the chamber orchestra present on stage and $p_{\text {empty }}$ is the pressure at the receiver with no orchestra present (empty stage), both integrated over suitable time windows to isolate the desired reflections. An analytic investigation of the arrival times of the direct sound, floor reflection, left wall, right wall, back wall and ceiling reflections (based on source and receiver locations used in Cases 1, 2 and 3) was provided in Figure $6 \mathrm{~d}$, e and $\mathrm{f}$ for the 'small' enclosure (which was based on the dimensions of the Hobart Town Hall).

Before investigating $\mathrm{SWC}_{\text {occ. - empty }}$ (Eq. 4) the impulse responses were truncated. Due to limitations in signal processing, it is impossible to isolate individual reflections without smearing from adjacent reflections, unless there is an appropriate gap where no sound energy in theory arrives, as discussed by Wenmaekers et al. ${ }^{8}$. Due to the size of the Hobart Town Hall, and the ornate features potentially causing scattering and diffusion, complete isolation of individual reflections is not possible; however, for comparison to the quantity $\mathrm{SWC}_{\mathrm{occ}}$ - - empty, excl. ceiling from the BEM model, a cutoff time of $23 \mathrm{~ms}$ was selected to isolate reasonably well the direct sound, the back wall, left wall and right wall reflections (prior to the occurrence of the ceiling reflection). To investigate the sensitivity to the cutoff time selected, the quantity

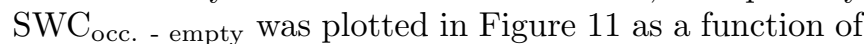
cutoff time for each case. In particular, for values in a $\pm 3 \mathrm{~ms}$ range around the $23 \mathrm{~ms}$ (i.e. $20-26 \mathrm{~ms}$ ) the change in $\mathrm{SWC}_{\text {occ. - empty was minimal (the largest variations }}$ seen over the $\pm 3 \mathrm{~ms}$ window were $\pm 0.5 \mathrm{~dB}$ for Case 1 , $\pm 1.1 \mathrm{~dB}$ for Case 2 and $\pm 0.2 \mathrm{~dB}$ for Case 3 across 125 $1000 \mathrm{~Hz}$ octave bands). The $\pm 1.1 \mathrm{~dB}$ variation for Case 2 was in the $1000 \mathrm{~Hz}$ octave band, and can be observed in Figure $11 \mathrm{~b}$ where $\mathrm{SWC}_{\mathrm{occ}}$ - empty is changing between 20-26 ms. The results for measurements compared to BEM are presented in Table $\mathrm{V}$ and for the $23 \mathrm{~ms}$ truncation the agreement is generally within $1 \mathrm{~dB}$. The worst result is for Case $1,1000 \mathrm{~Hz}$ and may be explained by the second-order reflections arriving close to $23 \mathrm{~ms}$ (see Figure 6d).

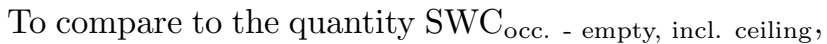
the signal was truncated at $40 \mathrm{~ms}$ for Cases 1 and 2, and at $43 \mathrm{~ms}$ for Case 3 , based on the arrival time of the ceiling (and ceiling/floor) reflection in each case, see Figure 6. The truncation times were selected to include the second-order ceiling/floor reflection because the floor reflection occurring after each first-order enclosure re- flection was inherent in the BEM model due to symmetry. This unavoidably included other second-order reflections which are not included in the BEM model.

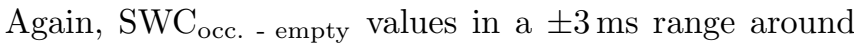
the $40 \mathrm{~ms}(37-43 \mathrm{~ms})$ were investigated for Cases 1 and 2 , and around the $43 \mathrm{~ms}(40-46 \mathrm{~ms})$ for Case 3 . The

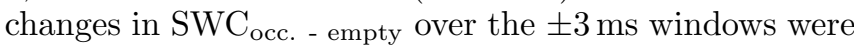
minimal (largest variations seen over the $\pm 3 \mathrm{~ms}$ window were $\pm 0.6 \mathrm{~dB}$ for Case $1, \pm 0.3 \mathrm{~dB}$ for Case 2 and $\pm 0.2 \mathrm{~dB}$ for Case 3 across $125-1000 \mathrm{~Hz}$ octave bands). The results for measurements compared to BEM are presented in Table $\mathrm{V}$, and for the $40 \mathrm{~ms}$ and $43 \mathrm{~ms}$ truncations the agreement is also generally within $1 \mathrm{~dB}$, with the exception of Case $21000 \mathrm{~Hz}$ which again may be explained by the second-order reflections not accounted for by the BEM model.

As mentioned, for the auditorium measurements three trials were conducted and the musicians were asked to relax and move in between trials (to represent some random perturbations in orchestra configuration). The results presented in Table $\mathrm{V}$ are an average of the three trials, however, the random perturbations introduced minimal change to results, with the largest change in $\mathrm{SWC}_{\text {occ. - empty }}(0-23$ or 0-40/43 ms truncation) between trials being $0.5 \mathrm{~dB}$ (across 125-1000 Hz bands and Cases $1-3)$.

Figure 11 shows that the difference between 'occupied' and 'empty' is greatest when the signal is truncated to include only the direct sound and floor reflection. When the signal is truncated later to include the early reflections, and in particular when it is truncated to include the unobstructed ceiling reflection (after around $30 \mathrm{~ms}$ ), the difference between 'occupied' and 'empty' becomes progressively less. However, these results show that over the first $50 \mathrm{~ms}$ of the impulse response there are quite significant differences between 'occupied' and 'empty', even when the unobstructed ceiling reflection is included.

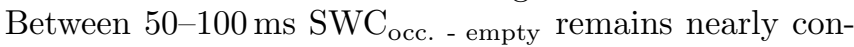
stant, indicating the main differences between 'occupied' and 'empty' on stage are occurring in the $0-50 \mathrm{~ms}$ time interval.

\section{DISCUSSION}

This paper shows how BEM may be used to model an orchestra on stage, including first order reflections modelled via symmetry planes. The strength of the BEM is its ability to model wave interference and diffraction rationally. This is in contrast to energy or ray-tracing methods, which can only treat wave effects empirically. Such effects are most prominent at wavelengths comparable in scale to the principal geometric features of the scattering bodies, that is from low frequencies up to roughly the upper end of the $1 \mathrm{kHz}$ octave band $(\lambda=240 \mathrm{~mm})$. The BEM models this range of frequencies particularly well. However every doubling of frequency requires four times as many elements to maintain the wavelength to el- 
(a)

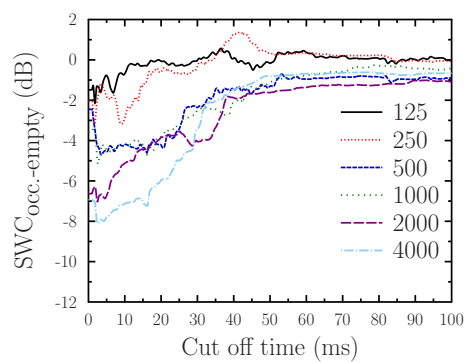

(b)

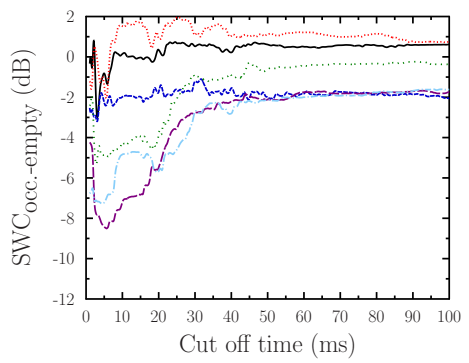

$(c)$

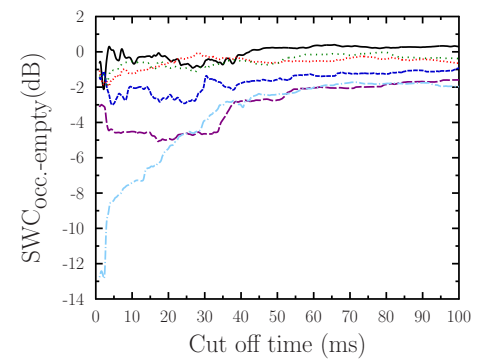

FIG. 11. (Color online) SWC $\mathrm{Scc}_{\text {. - empty }}(\mathrm{dB})$, as defined in Eq. 4, changing with cutoff time (s) for each case for measurements in the Hobart Town Hall with full scale chamber orchestra; (a) Case 1, (b) Case 2 and (c) Case 3.

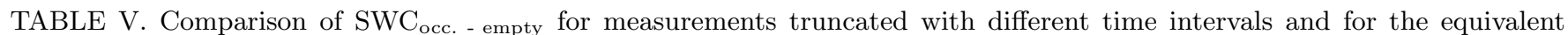

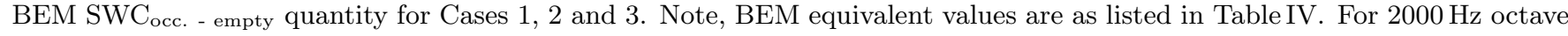
measurements results only are given.

\begin{tabular}{|c|c|c|c|c|c|c|c|}
\hline \multirow[b]{2}{*}{ Case } & \multirow[b]{2}{*}{$\begin{array}{c}\text { Octave } \\
(\mathrm{Hz})\end{array}$} & \multicolumn{3}{|c|}{$0-23 \mathrm{~ms}$} & \multicolumn{3}{|c|}{$0-40 / 43 \mathrm{~ms}$} \\
\hline & & Measurement & BEM equivalent & Difference & Measurement & BEM equivalent & Difference \\
\hline 1 & $\begin{array}{c}125 \\
250 \\
500 \\
1000 \\
2000 \\
\end{array}$ & $\begin{array}{c}0.0 \\
-0.3 \\
-3.8 \\
-3.4 \\
-3.8 \\
\end{array}$ & $\begin{array}{c}-0.1 \\
-1.1 \\
-4.1 \\
-5.5 \\
- \\
\end{array}$ & $\begin{array}{l}0.2 \\
0.9 \\
0.3 \\
2.1 \\
- \\
\end{array}$ & $\begin{array}{c}0.2 \\
1.2 \\
-1.6 \\
-2.0 \\
-2.0 \\
\end{array}$ & $\begin{array}{c}-0.1 \\
-1.1 \\
-3.7 \\
-4.8 \\
- \\
\end{array}$ & $\begin{array}{l}0.3 \\
2.4 \\
2.1 \\
2.9 \\
- \\
\end{array}$ \\
\hline 2 & $\begin{array}{c}125 \\
250 \\
500 \\
1000 \\
2000 \\
\end{array}$ & $\begin{array}{c}0.8 \\
1.6 \\
-1.9 \\
-3.0 \\
-3.8 \\
\end{array}$ & $\begin{array}{c}0.1 \\
0.0 \\
-2.4 \\
-3.8 \\
-\end{array}$ & $\begin{array}{c}0.7 \\
1.6 \\
0.5 \\
0.8 \\
-\end{array}$ & $\begin{array}{c}0.3 \\
1.1 \\
-1.7 \\
-1.0 \\
-2.0 \\
\end{array}$ & $\begin{array}{c}0.1 \\
0.0 \\
-2.2 \\
-3.4 \\
- \\
\end{array}$ & $\begin{array}{l}0.2 \\
1.1 \\
0.5 \\
2.4 \\
- \\
\end{array}$ \\
\hline 3 & $\begin{array}{c}125 \\
250 \\
500 \\
1000 \\
2000\end{array}$ & $\begin{array}{l}-0.4 \\
-0.4 \\
-2.9 \\
-0.8 \\
-5.1\end{array}$ & $\begin{array}{l}-0.4 \\
-2.1 \\
-2.4 \\
-1.2 \\
-\end{array}$ & $\begin{array}{c}0.0 \\
1.7 \\
-0.5 \\
0.3 \\
-\end{array}$ & $\begin{array}{c}0.1 \\
-0.5 \\
-1.9 \\
-0.6 \\
-3.2\end{array}$ & $\begin{array}{l}-0.4 \\
-1.9 \\
-2.4 \\
-1.1 \\
-\end{array}$ & $\begin{array}{l}0.5 \\
1.4 \\
0.5 \\
0.5 \\
-\end{array}$ \\
\hline
\end{tabular}

ement size ratio, requiring around 16 times more memory and comparable increases in computational time. Thus it is not yet practical to model an orchestra at high frequencies using BEM. Similarly very large orchestras, full complex stage enclosures or multiple symmetry planes are beyond the practical limits of BEM with current every-day computing resources. The high frequency problems may at least be dealt with by ray-tracing methods, since reflections become more specular in nature as wavelengths become small relative to the scattering bodies. However, judicious use of ray-tracing methods is recommended, as discussed in the introduction.

In Sections III B, III C and IV B results have been presented showing how a chamber orchestra on stage attenuates, or modifies via scattering, the direct sound and firstorder stage enclosure reflections. These findings have implications for the relevance of common on-stage acoustic parameters measured on an occupied, versus an unoccupied stage. This work demonstrates the effect that a chamber orchestra on stage would have on a parameter defined with a early time interval (0-50 ms); generally a $2-5 \mathrm{~dB}$ difference was found at $1 \mathrm{kHz}$ without the unobstructed ceiling reflection, a difference which was reduced slightly with the inclusion of the ceiling reflection. Excluding the direct sound (as is often done for common stage parameters) reduced the difference between occupied and empty in some cases, but even with direct sound excluded significant differences between occupied and empty were observed for $500 \mathrm{~Hz}$ and $1000 \mathrm{~Hz}$ (between 1-5 dB). The effect of the orchestra above $250 \mathrm{~Hz}$ appeared to be dependent on source-receiver path and stage enclosure size, and this highlights the difficulty with applying a correction to empty stage measurements to account for the orchestra, as found by others ${ }^{1,5}$.

The auditorium measurements agree well with the BEM model results, and confirm that these differences could be found over a $0-50 \mathrm{~ms}$ window in an actual hall. The auditorium measurements also show that the higher frequencies $(2-4 \mathrm{kHz})$ are attenuated as much (or slightly more) than the $1 \mathrm{kHz}$ octave band (see Figure 11). The 
BEM model only considered the equivalent of $0-50 \mathrm{~ms}$ as only first-order enclosure reflections were considered. Some commonly used stage parameters consider early sound up to $100 \mathrm{~ms}$, however the auditorium measurements indicate that the difference between occupied and empty mostly occurs over $0-50 \mathrm{~ms}: \mathrm{SWC}_{\text {occ. }}$ - empty after $50 \mathrm{~ms}$ is almost constant, indicating no further change between the occupied condition and empty condition (see Figure 11).

First-order stage reflections from the enclosure were investigated individually, showing that the angle of the sound path relative to the orchestra affected the results. Significant attenuation occurs for the direct sound, floor reflection, and side wall reflections; the ceiling reflection is not significantly attenuated by the orchestra.

The lack of ceiling attenuation (from the ensemble) produces strong comb filtering (if the ceiling reflection is specular). This highlights the possible positive role for scattering in reflective surfaces above stages. It also appears that the presence of the orchestra can reduce or remove significant comb filtering for the lateral first-order reflections. Work by others with symphony orchestras on stage has highlighted that discrete early reflections can cause coloration, and also that empty stage measurements are not necessarily a realistic representation of actual on-stage sound fields with the orchestra present, in terms of both timbre and ensemble. ${ }^{20}$ This work has yielded similar findings for a smaller chamber orchestra.

Previous studies have demonstrated the importance of lateral reflections on stage for ensemble playing and noted that overhead reflectors cannot compensate for a lack of early lateral energy from side walls ${ }^{12-14}$. A suggestion has been to tilt the top section of side walls to provide unattenuated lateral reflections ${ }^{12}$. In this study, the effect of the orchestra with incrementally varying elevation angle of an arriving reflection from the left was investigated for Case 1. This analysis found that for 500 and $1000 \mathrm{~Hz}$ octave bands attenuation by the orchestra is reduced as the angle of arrival moves away from horizontal, whereas for $250 \mathrm{~Hz}$ and below the results did not depend on angle. For this case tilting the sidewall by $30^{\circ}$ from vertical largely removed the effect of the orchestra.

This study focused on a standing chamber orchestra, a playing group which has not been studied in this way previously. The BEM model showed realistic and meaningful results, however the standing orchestra required $1.5 \mathrm{~m}$ source-receiver height, which due to the very different interference frequencies makes these results unable to be to compared directly to work by others who used 1 or $1.2 \mathrm{~m}$ heights $^{3,5}$. An interesting extension to this work would be to model a symphony orchestra with BEM.

\section{CONCLUSION}

This paper has focused on analyzing the effect of a chamber orchestra on on-stage sound fields, and has shown that even for a relatively small chamber orchestra on stage there is significant attenuation at some frequencies. This paper examined both attenuation of direct sound and attenuation of the first-order reflections from a stage enclosure. The ceiling reflections were not significantly affected by the orchestra. For the other firstorder reflections attenuation was found to be minimal at $125 \mathrm{~Hz}$. However, at $250 \mathrm{~Hz}$ and $500 \mathrm{~Hz}$ the attenuation was greater, but also more dependent on the sourcereceiver distance (due to the destructive inference between direct sound and floor reflection). The first-order reflections from the stage enclosure at $1000 \mathrm{~Hz}$ were often attenuated by $2-5 \mathrm{~dB}$ without including the unobstructed ceiling reflection, and slightly less when the unobstructed ceiling reflection was included. Additionally a tilted side wall case was studied, which showed at the 500 and $1000 \mathrm{~Hz}$ octaves lateral attenuation was significantly reduced as arrival angle rose above horizontal.

\section{ACKNOWLEDGMENTS}

The authors thank the volunteers who assisted with the anechoic measurements, as well as the volunteers who assisted with auditorium measurements. Lilyan Panton is supported by an Australian Postgraduate Award, with additional support from the Dr Joan Woodberry Postgraduate Fellowship in Engineering and the Georgina Sweet Fellowship. This research is supported under the Australian Research Council's Discovery Projects funding scheme (DP120100484).

2 A. C. Gade, "Investigations of musicians' room acoustic conditions in concert halls. ii: Field experiments and synthesis of results", Acta Acust. Acust. 69(6), 249-262, (1989) doi:10.1260/1351-010X.18.3-4.207
* Lilyan.Panton@utas.edu.au; Corresponding author.

1 J. J. Dammerud, "Stage acoustics for symphony orchestras in concert halls", PhD thesis, University of Bath, URL https://stageac.wordpress.com/, 2009 
3 J. J. Dammerud and M. Barron, "Attenuation of direct sound and the contributions of early reflections within symphony orchestras," J. Acoust. Soc. Am. 128(4), 1755-1765, (2010) doi:10.1121/1.3474235

4 M. Skålevik, "Sound transmission between musicians in a symphony orchestra on a concert hall stage", in Proc. of the 19th International Congress on Acoustics, Madrid (2007).

5 R. Wenmaekers, C. Hak and M. Hornikx, "How orchestra members influence stage acoustic parameters on five different concert hall stages and orchestra pits", J. Acoust. Soc. Am. 140(6), 4437-4448, (2016) doi:10.1121/1.4971763

6 A. C. Gade, "Practical aspects of room acoustic measurements on orchestra platforms", in Proc. of 14 th Inter. Congress on Acoustics, Beijing (1992).

7 E. W. van Den Braak and L. C. van Luxemburg, "New (stage) parameter for conductor's acoustics", in Proc. of Acoustics '08, Paris (2008).

${ }^{8}$ R. Wenmaekers, C. Hak, L. van Luxemburg, "On measurements of stage acoustic parameters - time interval limits and various source receiver distances", Acta Acust. Acust. 98(5), 776-789, (2012) doi:10.1260/1351-010X.18.3-4.207.

9 M. Ikeda, S. Kishinaga and F. Kawamaki, "Evaluating stage sound field for acoustic design based on boundary element method", in Forum Acusticum, Seville (2002).

${ }^{10}$ F. Martellotta, D. Michele, and S. Crociata, "Laboratory measurement of sound absorption of occupied pews and standing audiences, Appl. Acoust. 72(6), 341-349, (2010) doi:10.1016/j.apacoust.2010.12.008.

11 N. Adelman-Larsen, E. Thompson and A. C. Gade, "Suitable reverberation times for halls for rock and pop music," J. Acoust. Soc. Am. 127(1), 247-255 (2010) doi:10.1121/1.3263611.
12 J. J. Dammerud, M. Barron and E. Kahle, "Objective assessment of acoustic conditions for symphony orchestras", Build. Acoustics 18, 207-219, (2011) doi:10.1260/1351010X.18.3-4.207

13 A. Guthrie., "Stage acoustics for musicians: a multidimensional approach using 3D ambisonic technology", PhD thesis, Rensselaer Polytechnic Institute, Troy, New York, 2014

14 L. Panton, D. Holloway, D. Cabrera and L. Miranda," Stage acoustics in eight Australian concert halls: Acoustic conditions in relation to subjective assessments by a touring chamber orchestra", Acoustics Australia, "Inpress", (2016) doi:10.1007/s40857-016-0075-2.

15 A. Krokstad, J. Vindspoll, and R. Sæther. Orkesterpodium, samspill og solo (orchestra platform, ensemble and solo). Note on unpublished results of student works (in Norwegian), The Laboratory of Acoustics, The Technical University of Trondheim, 1980.

${ }^{16}$ H. Harwood, A. Burd, and N. Spring. "Acoustic scaling: Evaluation of the proving experiment," Technical report No. 1972/3, BBC Research Department, United Kingdom, 1972.

17 H. Jang and J. Jeon, "Acoustic characterization of on-stage performers in performing spaces", Appl. Acoust. 114, 159170, (2016) doi:10.1016/j.apacoust.2016.07.019

18 ISO-3382, Acoustics - Measurement of room acoustic parameters - Part 1: Performance spaces (International Organisation for Standardization, Geneva, Switerland, 2009).

19 T. J. Cox and P. D'Antonio. Acoustic absorbers and diffusers: theory, design and application. (Taylor and Francis, London and New York, 2009). pp. 442

20 T. Halmrast, "Orchestral timbre: Comb-filter coloration from reflections", J. Sound. Vib. 232, 53-69, (2000) doi:10.1006/jsvi.1999.2700

\footnotetext{
* Lilyan.Panton@utas.edu.au; Corresponding author.
} 